\title{
The relationship between glasgow prognostic score and serum tumor markers in patients with advanced non-small cell lung cancer
}

\author{
Ai-Gui Jiang ${ }^{1 *}$, Hong-Lin Chen ${ }^{2}$ and Hui-Yu Lu
}

\begin{abstract}
Background: Glasgow Prognostic Score (GPS) has been reported as a powerful prognostic tool for patients with advanced non-small cell lung cancer (NSCLC). The aim of this study was to assess the relationship between GPS and prognosis related tumor markers in patients with advanced NSCLC.
\end{abstract}

Methods: We included 138 advanced NSCLC patients and twenty healthy controls in the study. GPS was calculated by combined serum C-reactive protein (CRP) and albumin. Three serum tumor markers, which included cytokeratin 19 fragment antigen 21-1 (CYFRA21-1), carcinoembryonic antigen (CEA) and tissue polypeptide specific antigen (TPS), were detected by enzyme-linked immunosorbent assay (ELISA). GPS and tumor markers were all assessed before chemotherapy. All patients received at least 2 courses of cisplatin-based chemotherapy. After that, 2 to 5 years follow-up was conducted.

Results: Median levels of CYFRA21-1 were $1.5 \mathrm{ng} / \mathrm{ml}(0.1-3.1 \mathrm{ng} / \mathrm{ml})$ in healthy controls, and $4.6 \mathrm{ng} / \mathrm{ml}$ $(0.7-35.2 \mathrm{ng} / \mathrm{ml})$ in GPS 0 advanced NSCLC, $11.2 \mathrm{ng} / \mathrm{ml}(0.4-89.2) \mathrm{ng} / \mathrm{ml}$ in GPS 1 advanced NSCLC, and $15.7 \mathrm{ng} / \mathrm{ml}$ $(2.9-134.6 \mathrm{ng} / \mathrm{ml})$ in GPS 2 advanced NSCLC, respectively. Median levels of CYFRA21-1 were higher in NSCLC patients than in healthy controls, and CYFRA21-1 increased gradually according to GPS category in NSCLC patients $(P<0.05)$. Similar results were found for median levels of CEA and TPS in healthy controls and NSCLC patients $(P<0.05)$. In NSCLC patients, positive correlations were found between CYFRA21-1 and GPS, CEA and GPS, TPS and GPS. The Spearman's rank correlation coefficient were $0.67(P<0.05), 0.61(P<0.05)$ and $0.55(P<0.05)$, respectively. Survival analyses showed GPS was an independent prognostic factor for advanced NSCLC. CYFRA21-1 $(>3.3 \mathrm{ng} / \mathrm{ml})$ and TPS (>80 U/I) were related with the prognosis of advanced NSCLC by univariate analyses, but multivariate analyses showed CYFRA21-1, TPS and CEA were not the independent prognostic factors for advanced NSCLC.

Conclusions: Our results showed GPS were positive correlated with CYFRA21-1, CEA and TPS in patients with advanced NSCLC. However, GPS was more efficient in predicting prognosis of advanced NSCLC than these three single prognosis related tumor markers.

Keywords: Advanced non-small cell lung cancer, Glasgow prognostic score, CYFRA21-1, CEA, TPS

\section{Background}

Although many progresses have been made in targeted therapy, chemotherapy and radiotherapy in recent years, the prognosis of advanced Non-small cell lung cancer (NSCLC) is still poor, with the median overall survival 30.5 months and the median progression-free survival

\footnotetext{
*Correspondence: pphss@126.com

'Department of Respiratory Diseases, Jiangsu Taizhou People's Hospital, Yingchun Road 210\#, Taizhou City 225300, Jiangsu Province, P R China
} Full list of author information is available at the end of the article
10.8 months [1]. Accurate prediction of prognosis outcome in advanced NSCLC also remains challenging. Even within the same stage, same performance status, same treatment group and same response to treatment, survival varies from patient to patient [2].

Inflammatory responses play decisive roles at different stages of tumor development, including initiation, promotion, malignant conversion, invasion and metastasis [3]. Glasgow prognostic score (GPS), a inflammationbased scoring system, was found an useful tool in 
predicting prognosis for gastric cancer [4], colorectal cancer [5], pancreatic cancer [6], hepatocellular cancer [7], esophageal cancer [8], and cervical cancer [9]. In NSCLC patients, our previous study has also found GPS was a useful and important predictor of progression free survival (PFS) and overall survival (OS) [10]. This conclusion also confirmed by other studies [11-13].

In addition, several tumor markers have been described to be independently relevant for estimation of prognosis in terms of overall or progression-free survival in NSCLC patients [14]. Cytokeratin 19 fragment antigen 21-1 (CYFRA21-1) is a cytokeratin expressed in simple epithelium, which has been extensively studied in patients with NSCLC has been demonstrated to be clinically useful. Serum concentrations of CYFRA 21-1 correlate with tumor burden, and CYFRA $21-1$ is an independent prognostic factor for NSCLC [15-17]. Carcinoembryonic antigen (CEA) is an oncofetal glycoprotein of the cell surfaces. The NSCLC patients with a persistently high serum CEA level after had worst prognosis [18, 19]. One study showed patients with normal preoperative serum CEA levels had better 5 year survival than patients with high preoperative serum CEA levels $(71.1 \%$ versus $54.6 \%, P=0.016$ ) [20]. Tissue polypeptide specific antigen (TPS) is another important prognosis related tumor markers which has been confirmed by many studies [21, 22].

GPS and some tumor markers also have prognosis predicting value in patients with NSCLC. However, the relationship between GPS and tumor markers level is still unknown. The aim of the present study was to examine the relationship between an inflammation-based GPS and prognosis related tumor markers (CYFRA21-1, CEA and TPS) level in patients with NSCLC.

\section{Methods \\ Patients}

Between January 2008 and January 2011, consecutive patients with stage IIIB or IV NSCLC were enrolled in this prospective cohort study. All NSCLC diagnosis was confirmed by cytological or histological examination. Clinical staging was based on clinical findings, chest X-ray, computed tomography of the chest, abdomen, brain and bone scintigraphy. Basic demographics, which included age, gender, histological type, smoking status and Eastern Cooperative Oncology Group Performance Status (ECOG's PS) were recorded before chemotherapy. We also enrolled 20 healthy volunteers as control group. The volunteers have compared age, sex and smoking status with NSCLC patients. The study was approved by the Ethics Committee of Taizhou hospital, and all patients and healthy control signed an informed consent before inclusion in the study.

\section{GPS system}

GPS were defined by combined serum C-reactive protein (CRP) and albumin [4-13]. Patients with a CRP $<10 \mathrm{mg} / \mathrm{L}$ and albumin $>35 \mathrm{~g} / \mathrm{L}$ were allocated to GPS 0 . If only CRP was increased or albumin decreased patients were allocated to the GPS 1 , and patients in whom CRP was $>10 \mathrm{mg} / \mathrm{L}$ and albumin level $<35 \mathrm{~g} / \mathrm{L}$ were classified as GPS 2 .

Before chemotherapy, $10 \mathrm{ml}$ blood sample was collect. $5 \mathrm{ml}$ sample was sent to the laboratory immediately. $\mathrm{CPR}$ and albumin concentration were examined by routine laboratory measurements. After that, GPS was calculated.

\section{Serum tumor markers}

The remaining $5 \mathrm{ml}$ serum sample was stored at $-20{ }^{\circ} \mathrm{C}$ for future analysis. CYFRA21-1, CEA and TPS measured by enzyme-linked immunosorbent assay (ELISA) using commercially available assay kits (Immuno-Biological Laboratories, Gunma, Japan). All operations were followed by manufacturer's instructions. As recommended by the manufacturers, the following cut-offs for serum levels were used initially: CYFRA21-1 $3.3 \mathrm{ng} / \mathrm{ml}$, CEA $5 \mathrm{ng} / \mathrm{ml}$, and TPS $80 \mathrm{U} / \mathrm{l}$.

\section{Treatment and follow-up}

Patients with ECOG's PS $0-1$ received at least 2 courses of cisplatin-based chemotherapy and received courses until the appearance of progressive disease. The cisplatinbased regimens were vinorelbine $\left(25 \mathrm{mg} / \mathrm{m}^{2}\right)$ on days 1 and 8 plus cisplatin $\left(80 \mathrm{mg} / \mathrm{m}^{2}\right)$ on day 1 of a 21-day cycle, and gemcitabine $\left(1000 \mathrm{mg} / \mathrm{m}^{2}\right)$ on days 1 and 8 plus cisplatin $\left(80 \mathrm{mg} / \mathrm{m}^{2}\right)$ on day 1 of a 21-day cycle. Patients with ECOG's PS 2 received docetaxel $\left(75 \mathrm{mg} / \mathrm{m}^{2}\right)$ on days 1 and docetaxel $\left(35 \mathrm{mg} / \mathrm{m}^{2}\right)$ on days 1 , days 8 and days 21 every 3 weeks. Patients with ECOG's PS 3 only received best support care.

All patients received 3 to 5 years follow-up. The outcomes included progression free survival (PFS) and overall survival (OS).

\section{Statistical analysis}

Data are presented as medians, with ranges. The chi-square test was used for categorical data (compare characteristics between NSCLC patients and healthy controls). The Kruscal-Wallis $\mathrm{H}$ test was used for non-normal distribution continuous data for more than two populations (compare tumor markers between GPS 0, GPS 1, GPS 2 NSCLC patients and healthy controls). Associations between GPS and the level of serum tumor markers were analyzed using Spearman's rank correlation coefficient. Survival analyses were conducted by univariate Kaplan-Meier method and multivariate Cox proportional hazards model. Results were presented as hazard ratio (HR) with $95 \%$ confidence interval $(95 \% \mathrm{CI}) . P<0.05$ was considered significant. All 
statistical analyses were performed using IBM SPSS statistics software (version 19.0, IBM, Armonk, NY).

\section{Results}

Characterization of NSCLC patients and healthy controls One hundred thirty-eight NSCLC patients were included in the study. Patients' median age was 55 years (range, 37-81years), 63 (45.7\%) patients $>60$ years, 117 (84.8\%) patients were male, and $42(30.4 \%)$ patients were smokers. 20 healthy controls and 138 NSCLC patients were similar in terms of age, gender and smoking status. In 138 NSCLC patients, $67(48.6 \%)$ patients had squamous cell carcinoma and 56 (59.6\%) had stage IV disease. and 82 (59.5\%) patients had an ECOG performance status 0 or 1 . Characteristics of healthy controls and NSCLC patients were listed in Table 1.

\section{Relationship between GPS and serum tumor markers} Median levels of CYFRA21-1 were $1.5 \mathrm{ng} / \mathrm{ml} \mathrm{(0.1-}$ $3.1 \mathrm{ng} / \mathrm{ml}$ ) in healthy controls. In NSCLC patients, median levels of CYFRA21-1 were $4.6 \mathrm{ng} / \mathrm{ml}(0.7-35.2 \mathrm{ng} /$ $\mathrm{ml})$ in GPS 0, $11.2 \mathrm{ng} / \mathrm{ml}(0.4-89.2) \mathrm{ng} / \mathrm{ml}$ in GPS 1 , and $15.7 \mathrm{ng} / \mathrm{ml}(2.9-134.6 \mathrm{ng} / \mathrm{ml})$ in GPS 2, respectively. The Kruscal-Wallis $\mathrm{H}$ test showed median levels of CYFRA211 were significant different between four groups $(P<0.05)$. Median levels of CYFRA21-1 were higher in NSCLC patients than in healthy controls. In NSCLC patients, median levels of CYFRA21-1 increased gradually according to GPS category. Similar results were found for median levels of CEA and TPS in healthy controls and NSCLC patients $(P<0.05)$. Figure 1 showed the trends of 3 serum tumor markers in healthy controls and NSCLC patients.

In NSCLC patients, positive correlation was found between CYFRA21-1 and GPS. The Spearman's rank correlation coefficient was $0.67(P<0.05)$. Positive correlations were also found between CEA and GPS, TPS and GPS. The correlation coefficient were $0.61(P<0.05)$ and 0.55 $(P<0.05)$, respectively.

\section{The relationship between advanced NSCLC prognosis and GPS and serum tumor markers}

Univariate analyses showed GPS was related with the prognosis of advanced NSCLC. After adjusted by patients' age, gender, smoking status, histologic type, tumor stage, performance status and serum tumor markers, the multivariate analyses confirmed that GPS was an independent prognostic factor for advanced NSCLC.

For serum tumor markers, CYFRA21-1 $(>3.3 \mathrm{ng} / \mathrm{ml})$ and TPS $(>80 \mathrm{U} / \mathrm{l})$ were related with the prognosis of advanced NSCLC by univariate analyses, but multivariate analyses showed CYFRA21-1 and TPS were not the independent prognostic factors for advanced NSCLC. In univariate analyses and multivariate analyses, CEA $(>5 \mathrm{ng} / \mathrm{ml}$ ) also didn't show the relationship with the prognosis of advanced NSCLC.

Details of univariate and multivariate survival analyses were listed in the Table 2, and survival curves stratified by GPS and serum tumor markers were shown in Fig. 2 .

\section{Discussion}

Lung cancer is the most common cancer in world. Each year, nearly $1,708,800$ patients were diagnosed with lung cancer and over 1,378,400 die, corresponding to an annual age-standardized rate of 47.4 cases per 100,000 patients, annual age-standardized mortality rate of 39.4 deaths per 100,000 in more developed areas [23]. GPS was found a useful prognosis predictor in patients with NSCLC. Serum tumor markers, such as CYFRA21-1, CEA and TPS have been also confirmed as important prognosis risk factors for NSCLC [14-22]. The aim of the present study was to examine the relationship between GPS and prognosis related tumor markers (CYFRA21-1, CEA and TPS) level in patients with NSCLC. We found the median levels of CYFRA21-1, CEA and TPS were all higher in patients with NSCLC compared with healthy controls. In patients with NSCLC, CYFRA21-1, CEA and TPS were all increased gradually according to GPS. The Spearman's rank correlation showed positive correlations existing between these three tumor markers and GPS in NSCLC patients. Brown DJ and his colleagues also compared GPS and serum biochemical variables in patients with advanced lung and gastrointestinal cancer, they also found found GPS were correlated with the biochemical variables, which included sodium, chloride, creatine kinase, zinc, vitamin D, calcium, copper, alkaline phosphatase, gamma-glutamyl transferaseand lactate

Table 1 Characteristics of healthy controls and NSCLC patients

\begin{tabular}{|c|c|c|c|c|}
\hline Characteristics & Healthy controls $(n=20)$ & NSCLC patients $(n=138)$ & $x^{2}$ & $P$ Value \\
\hline Age $(\leq 60 />60)$ & $12 / 8$ & $75 / 60$ & 0.140 & 0.709 \\
\hline Gender (M/F) & $16 / 4$ & $117 / 21$ & 0.300 & 0.584 \\
\hline Smoking status $(\mathrm{Y} / \mathrm{N})$ & $6 / 14$ & $42 / 96$ & 0.002 & 0.968 \\
\hline Histologic type (Squ/Ade/Oth) & N/A & $67 / 48 / 23$ & N/A & N/A \\
\hline Stage (IIIB/IV) & N/A & $53 / 83$ & $\mathrm{~N} / \mathrm{A}$ & N/A \\
\hline Performance status $(0 / 1 / 2 / 3)$ & N/A & $35 / 47 / 32 / 24$ & N/A & N/A \\
\hline
\end{tabular}

Squ, Squamous cell carcinoma; Ade, Adenocarcinoma; Oth, Others; N/A, Not applicable. 


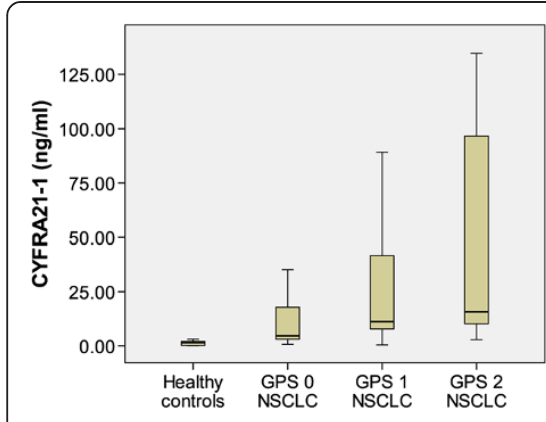

A

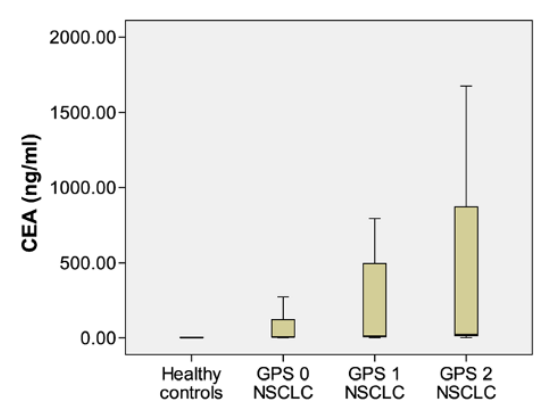

B

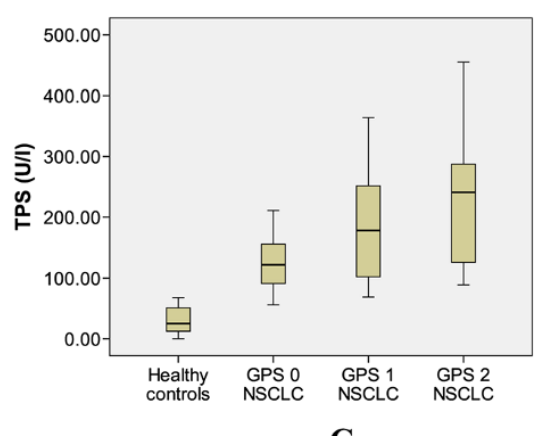

C

Fig. 1 The distribution of three tumor markers in healthy control $(n=20)$ and NSCLC patients $(G P S 0 n=95 ;$ GPS $1 n=32 ;$ GPS $2 n=11)$. A cytokeratin 19 fragment (CYFRA21-1) concentration was significant deferent between four groups (P<0.05); B: carcinoembryonic antigen (CEA) concentration was significant deferent between four groups $(\mathrm{P}<0.05)$; $\mathbf{C}$ : tissue polypeptide specific antigen (TPS) concentration was significant deferent between four groups $(P<0.05)$

dehydrogenase [24]. This conclusion was same as our study.

Some possible mechanisms maybe explain these correlations between GPS and tumor markers. GPS is a cancer prognosis predicting system based on inflammation scoring. Studies have confirmed that inflammatory activate immune cells product cytokines, such as NF- $\kappa B$, STAT3, AP-1, FOXP3 and interleukin, which can stimulate cancer cell proliferation and survival. That is a major tumor-promoting mechanism for inflammatory [3]. A recent study showed the relative expression of transcription factor FOXP3 tended to increase expression of cytokeratin 19 [25]. Kim et al. also found transcription factor $N F-\kappa B$ were related with elevated carcinoembryonic antigen level [26]. For tumor marker TPS, Kramer et al. found TPS increased along with interleukin-8 (IL-8) [27]. Inflammation promote angiogenesis is another important mechanism for tumor promote and metastasis. Important proangiogenic genes, such as VEGF, CXCL1, CXCL8, IL-8 and HIF1a, are directly regulated by inflammatory cytokines [3]. Yang et al. reported the level of cytokeratin 19 was related to tumor angiogenesis [28]. VEGF is regarded as the strongest angiogenic factor, which has been found related with carcinoembryonic antigen [29].

Although we found GPS are positive correlated with these tumor markers (CYFRA21-1, CEA and TPS) and in advanced NSCLC patients. Survival analyses showed GPS was an independent prognostic factor for advanced NSCLC. While CYFRA21-1(>3.3 ng/ml), CEA ( $>5 \mathrm{ng} / \mathrm{ml})$, and TPS $(>80 \mathrm{U} / \mathrm{l})$ were not the independent prognostic factors for advanced NSCLC. It seems GPS was more efficient in predicting prognosis of advanced NSCLC than these three single prognosis related tumor markers. No other studies were found for assessing prognosis of lung cancer by combine GPS and tumor markers. While in colorectal cancer patients, Choi KW et al. found CEA and GPS were associated with cancer-specific survival in univariate analysis, but only GPS was identified as independent prognostic factors in multivariate analysis [30]. In gastric cancer patients, Jiang $\mathrm{X}$ et al. reported increased GPS, elevated CEA and CA19-9 predicted a higher risk of postoperative mortality in both relative early-stage (stage I; $P<0.001$ ) and advanced-stage cancer (stage II, III

Table 2 Relationship between advanced NSCLC prognosis and GPS and serum tumor markers in 138 patients

\begin{tabular}{|c|c|c|c|c|c|c|c|c|}
\hline \multirow[t]{3}{*}{ Characteristics } & \multicolumn{4}{|c|}{ Disease-Free survival } & \multicolumn{4}{|c|}{ Overall survival } \\
\hline & \multicolumn{2}{|l|}{ Univariate } & \multicolumn{2}{|l|}{ Multivariate } & \multicolumn{2}{|l|}{ Univariate } & \multicolumn{2}{|l|}{ Multivariate } \\
\hline & $\mathrm{HR}(95 \% \mathrm{Cl})$ & $P$ & $\mathrm{HR}(95 \% \mathrm{Cl})$ & $P$ & $\mathrm{HR}(95 \% \mathrm{Cl})$ & $P$ & $\mathrm{HR}(95 \% \mathrm{Cl})$ & $P$ \\
\hline \multicolumn{9}{|l|}{ GPS } \\
\hline 0 & 1 & $0.01^{*}$ & 1 & $0.03^{*}$ & 1 & $0.02^{*}$ & 1 & $0.02^{*}$ \\
\hline 1 & $0.7(0.4-0.9)$ & & $0.8(0.5-0.9)$ & & $0.8(0.5-0.9)$ & & $0.8(0.4-0.9)$ & \\
\hline 2 & $0.5(0.2-0.8)$ & & $0.6(0.2-0.8)$ & & $0.5(0.3-0.8)$ & & $0.5(0.2-0.9)$ & \\
\hline CYFRA21-1 (>3.3 ng/ml) & $0.6(0.5-0.9)$ & $0.03^{*}$ & $0.7(0.5-1.0)$ & 0.08 & $0.7(0.3-0.9)$ & $0.04^{*}$ & $0.8(0.5-1.0)$ & 0.07 \\
\hline CEA (>5 ng/ml) & $0.7(0.4-1.1)$ & 0.13 & $0.7(0.5-1.2)$ & 0.17 & $0.8(0.5-1.1)$ & 0.19 & $0.8(0.6-1.3)$ & 0.19 \\
\hline TPS (>80 U/l) & $0.7(0.5-0.9)$ & $0.04^{*}$ & $0.7(0.5-1.1)$ & 0.12 & $0.8(0.5-1.0)$ & 0.05 & $0.8(0.4-1.1)$ & 0.13 \\
\hline
\end{tabular}




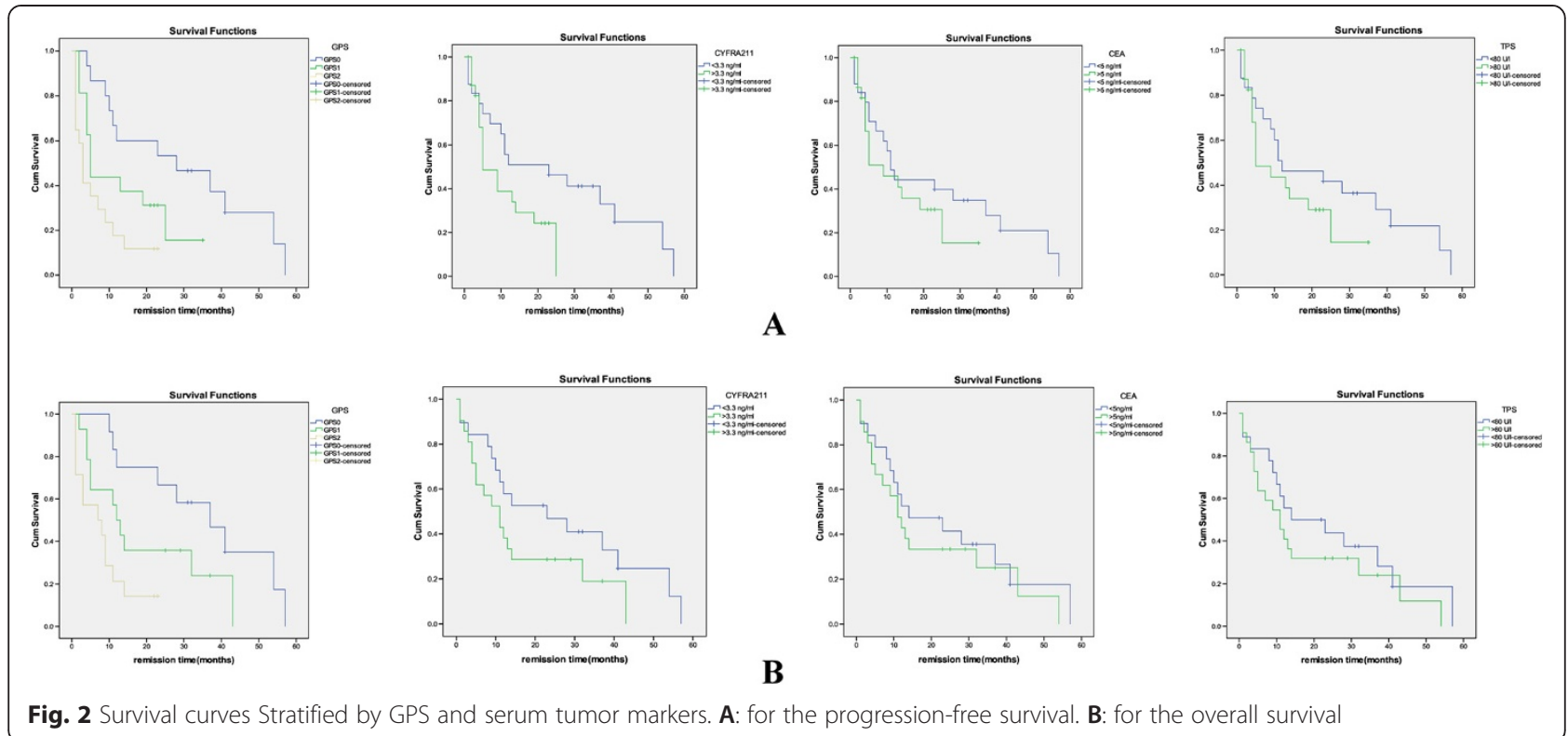

and IV; $P<0.001)$ in univariate Kaplan-Meier analysis; but in multivariate analysis, only GPS predicted postoperative mortality (OR $1.845 ; 95 \%$ CI $1.184-2.875 ; P=0.007$ ), not CEA (OR 1.234; 95\% CI 0.955-1.595; $P=0.107$ ) and CA19-9 (OR 1.213; 95\% CI 0.916-1.605; $P=0.177$ ) [31]. These results were same like our study.

There was a limitation in our study. We only investigated the relationship between GPS and tumor markers before chemotherapy. Chemotherapy treatment may change GPS and serum tumor markers level, and the change of GPS and serum tumor markers level may be related with chemotherapy response. We don't know whether this relationship will continue to exist. However, some blood samples were lost in the follow-up.

\section{Conclusions}

The results of the present study show that GPS were positive correlated with CYFRA21-1, CEA and TPS in patients with advanced NSCLC. However, GPS was more efficient in predicting prognosis of advanced NSCLC than these three single prognosis related tumor markers.

\section{Competing interests}

The authors declare that they have no competing interests.

\section{Authors' contributions}

A-GJ participated in the design of the study, acquisition of data and drafting the article or revising it. H-LC participated in the statistical analysis, and drafting the article or revising it. H-YL participated in the design of the study and acquisition of data. All authors read and approved the final manuscript.

\section{Acknowledgments}

We thank the anonymous reviewers for several insightful comments that significantly improved the paper.

\section{Author details}

'Department of Respiratory Diseases, Jiangsu Taizhou People's Hospital, Yingchun Road 210\#, Taizhou City 225300, Jiangsu Province, P R China. ${ }^{2}$ Nantong University, Qixiu Road 19\#, Nantong city 226001, Jiangsu Province, P R China.

Received: 24 September 2014 Accepted: 29 April 2015 Published online: 10 May 2015

\section{References}

1. Maemondo M, Inoue A, Kobayashi K, Sugawara S, Oizumi S, Isobe H, et al. Gefitinib or chemotherapy for non-small-cell lung cancer with mutated EGFR. N Engl J Med. 2010;362(25):2380-8.

2. Govindan R, Bogart J, Vokes EE. Locally advanced non-small cell lung cancer: the past, present, and future. J Thorac Oncol. 2008;3(8):917-28.

3. Grivennikov SI, Greten FR, Karin M. Immunity, inflammation, and cancer. Cell. 2010;140(6):883-99.

4. Mimatsu K, Oida T, Fukino N, Kano H, Kawasaki A, Kida K, et al. Glasgow prognostic score is a useful predictive factor of outcome after palliative gastrectomy for stage IV gastric cancer. Anticancer Res. 2014;34(6):3131-6.

5. Dreanic J, Dhooge M, Brezault C, Mir O, Chaussade S, Coriat R. A prognostic indicator of survival in metastatic colorectal cancer patients in the era of molecular-targeted agents: the modified Glasgow Prognostic Score. Oncology. 2014;86(1):44-5.

6. La Torre M, Nigri G, Cavallini M, Mercantini P, Ziparo V, Ramacciato G. The glasgow prognostic score as a predictor of survival in patients with potentially resectable pancreatic adenocarcinoma. Ann Surg Oncol. 2012;19(9):2917-23.

7. Horino K, Beppu T, Kuroki H, Mima K, Okabe H, Nakahara O, et al. Glasgow Prognostic Score as a useful prognostic factor after hepatectomy for hepatocellular carcinoma. Int J Clin Oncol. 2013;18(5):829-38.

8. Vashist YK, Loos J, Dedow J, Tachezy M, Uzunoglu G, Kutup A, et al. Glasgow Prognostic Score is a predictor of perioperative and long-term outcome in patients with only surgically treated esophageal cancer. Ann Surg Oncol. 2011;18(4):1130-8.

9. Polterauer S, Grimm C, Seebacher V, Rahhal J, Tempfer C, Reinthaller A, et al. The inflammation-based Glasgow Prognostic Score predicts survival in patients with cervical cancer. Int J Gynecol Cancer. 2010;20(6):1052-7.

10. Jiang AG, Lu HY. The Glasgow prognostic score as a prognostic factor in patients with advanced non-small cell lung cancer treated with cisplatin-based first-line chemotherapy. J Chemother. 2015;27(1):35-9. 
11. Tomita M, Ayabe T, Chosa E, Nakamura K. Prognostic significance of Pre- and postoperative Glasgow prognostic score for patients with Non-small cell lung cancer. Anticancer Res. 2014;34(6):3137-40.

12. Umihanic S, Umihanic S, Jamakosmanovic S, Brkic S, Osmic M, Dedic S, et al. Glasgow prognostic score in patients receiving chemotherapy for non-small-cell lung cancer in stages IIIb and IV. Med Arh. 2014;68(2):83-5.

13. Leung EY, Scott HR, McMillan DC. Clinical utility of the pretreatment glasgow prognostic score in patients with advanced inoperable non-small cell lung cancer. J Thorac Oncol. 2012;7(4):655-62.

14. Holdenrieder $S$, Nagel D, Stieber P. Estimation of prognosis by circulating biomarkers in patients with non-small cell lung cancer. Cancer Biomark. 2010;6(3-4):179-90.

15. Cedrés $S$, Nuñez I, Longo M, Martinez $P$, Checa E, Torrejón D, et al. Serum tumor markers CEA, CYFRA21-1, and CA-125 are associated with worse prognosis in advanced non-small-cell lung cancer (NSCLC). Clin Lung Cancer. 2011;12(3):172-9.

16. Pujol JL, Molinier O, Ebert W, Daurès JP, Barlesi F, Buccheri G, et al. CYFRA 21-1 is a prognostic determinant in non-small-cell lung cancer: results of a meta-analysis in 2063 patients. Br J Cancer. 2004;90(11):2097-105.

17. Trapé J, Buxo J, Pérez de Olaguer J, Vidal C. Tumor markers as prognostic factors in treated non-small cell lung cancer. Anticancer Res. 2003;23(5b):4277-81.

18. Matsuguma H, Nakahara R, Igarashi S, Ishikawa Y, Suzuki H, Miyazawa N, et al. Pathologic stage I non-small cell lung cancer with high levels of preoperative serum carcinoembryonic antigen: clinicopathologic characteristics and prognosis. J Thorac Cardiovasc Surg. 2008;135(1):44-9.

19. Kozu Y, Maniwa T, Takahashi S, Isaka M, Ohde Y, Nakajima T. Prognostic significance of postoperative serum carcinoembryonic antigen levels in patients with completely resected pathological-stage I non-small cell lung cancer. J Cardiothorac Surg. 2013;8(1):106.

20. Wang CY, Huang MS, Huang MH, Lee HC, Hsu HS. Persistently high serum carcinoembryonic antigen levels after surgery indicate poor prognosis in patients with stage I non-small-cell lung cancer. J Surg Res. 2010;163(2):e45-50.

21. van der Gaast A, Schoenmakers CH, Kok TC, Blijenberg BG, Hop WC, Splinter TA. Prognostic significance of tissue polypeptide-specific antigen (TPS) in patients with advanced non-small cell lung cancer. Eur J Cancer. 1994;30A(12):1783-6.

22. Chen F, Luo X, Zhang J, Lu Y, Luo R. Elevated serum levels of TPS and CYFRA 21-1 predict poor prognosis in advanced non-small-cell lung cancer patients treated with gefitinib. Med Oncol. 2010;27(3):950-7.

23. Jemal A, Bray F, Center MM, Ferlay J, Ward E, Forman D. Global cancer statistics. CA Cancer J Clin. 2011;61(2):69-90.

24. Brown DJ, Milroy R, Preston T, McMillan DC. The relationship between an inflammation-based prognostic score (Glasgow Prognostic Score) and changes in serum biochemical variables in patients with advanced lung and gastrointestinal cancer. J Clin Pathol. 2007;60(6):705-8.

25. Hanagiri T, Fukumoto M, Koyanagi Y, Furutani Y, Tanaka F. Regulatory T-cells and micrometastasis in lymph nodes of stage I NSCLC. Anticancer Res. 2014;34(12):7185-90.

26. Kim NK, Park JK, Shin E, Kim YW. The combination of nuclear factor kappa B, cyclo-oxygenase-2 and vascular endothelial growth factor expression predicts poor prognosis in stage II and III colorectal cancer. Anticancer Res. 2014:34(11):6451-7.

27. Kramer G, Steiner GE, Sokol P, Handisurya A, Klingler HC, Maier U, et al. Local intratumoral tumor necrosis factor-alpha and systemic IFN-alpha $2 \mathrm{~b}$ in patients with locally advanced prostate cancer. J Interferon Cytokine Res. 2001;21(7):475-84

28. Yang XR, Xu Y, Yu B, Zhou J, Qiu SJ, Shi GM, et al. High expression levels of putative hepatic stem/progenitor cell biomarkers related to tumour angiogenesis and poor prognosis of hepatocellular carcinoma. Gut. 2010;59(7):953-62

29. Park KW, Kim SJ, Oh SY. Clinicopathologic significance of nuclear factor-KB and vascular endothelial growth factor expression in advanced gastric cancer patients. Oncol Res Treat. 2014;37(4):183-90.

30. Choi KW, Hong SW, Chang YG, Lee WY, Lee B, Paik IW, et al. Inflammationbased score (Glasgow prognostic score) as an independent prognostic factor in colorectal cancer patients. Ann Surg Treat Res. 2014;86(6):309-13.

31. Jiang $X$, Hiki N, Nunobe S, Kumagai K, Kubota T, Aikou S, et al. Prognostic importance of the inflammation-based Glasgow prognostic score in patients with gastric cancer. Br J Cancer. 2012;107(2):275-9.

\section{Submit your next manuscript to BioMed Central and take full advantage of:}

- Convenient online submission

- Thorough peer review

- No space constraints or color figure charges

- Immediate publication on acceptance

- Inclusion in PubMed, CAS, Scopus and Google Scholar

- Research which is freely available for redistribution

Submit your manuscript at www.biomedcentral.com/submit 